\title{
Cristianismo y liberación en El Salvador: el boletín católico Justicia y $\mathrm{Paz}, 1972-1980^{1}$ \\ Julián GonZÁLEZ TORRES \\ Departamento de Filosofía \\ UCA, San Salvador
}

\begin{tabular}{|c|c|}
\hline $\begin{array}{l}\text { RESUMEN: El presente texto pretende } \\
\text { ser un modesto ensayo de "bistorización } \\
\text { de las ideas". En este sentido, el autor } \\
\text { rastrea qué concepto de sociedad salva- } \\
\text { doreña, de campesino y de liberación se } \\
\text { propuso en el boletin cristiano Justicia y } \\
\text { Paz en la década de } 1970 \text { en El Salvador; } \\
\text { esto habida cuenta del influjo del Vatica- } \\
\text { no II (1962-1965) y de la II Conferencia } \\
\text { Episcopal Latinoamericana en Medellín } \\
\text { (1968) en dicho boletin. }\end{array}$ & $\begin{array}{l}\text { ABSTRACT: The following text pretends } \\
\text { to be a modest essay of "bistorization of } \\
\text { ideas". In this sense, the author surveys } \\
\text { which concept of Salvadoran society, of } \\
\text { peasant and liberation was proposed in } \\
\text { the Christian bulletin Justicia y Paz, in } \\
\text { the decade of } 1970 \text { in El Salvador, con- } \\
\text { sidering the influence of the II Vatican } \\
\text { Council (1962-1965) and of the II Latin } \\
\text { American Episcopal Conference in Me- } \\
\text { dellin (1968). }\end{array}$ \\
\hline
\end{tabular}

La liberación de América Latina brotará de nuestros brazos hermanos, manos, nervios, sangre; brotará, es cierto, como la cosecha que el sudor arranca del fondo de la tierra.

Justicia y Paz, Número 18, 1973.

\section{Introducción}

Juan Carlos Scannone, filósofo argentino, sostiene que la apuesta del cristianismo latinoamericano por la liberación del ser humano ha constituido un aporte original a la reflexión filosófica del continente. Este 
autor declara lo siguiente: "Estimo que tanto Medellín como la teología de la liberación son los primeros testimonios de un aporte original que el cristianismo latinoamericano iba a dar a la problemática filosófica en general y, en particular, de la religión, aporte que se puede condensar en la palabra "liberación"”’2. Ese aporte original está estrechamente relacionado con el surgimiento en 1971 en Argentina del movimiento denominado "Filosofía de la liberación". Scannone mismo formó parte del grupo de jóvenes filósofos que estaban a la base de dicho movimiento $^{3}$.

El Concilio Vaticano II (1962-1965) y la II Conferencia del Episcopado Latinoamericano en Medellín (1968) condujeron a muchos cristianos latinoamericanos a un discernimiento crítico de las condiciones socio-históricas de los pueblos del continente a la luz de la palabra de Dios; este discernimiento, apoyado en diversas ciencias sociales, contribuyó enormemente al esclarecimiento de las condiciones sociales de injusticia y opresión y a la búsqueda de formas de liberación. Según Scannone, esta búsqueda de la liberación humana desde la praxis del cristianismo constituyó un aporte original a la reflexión filosófica, en general, y a la filosofía de la religión, en particular.

Motivado, en términos generales, por el diálogo que se da entre religión y filosofía en el campo de la filosofía de la religión y, en particular, por esa estrecha relación que establece Scannone entre cristianismo latinoamericano y pensamiento filosófico, decidí indagar qué aportes pudo haber dado la iglesia cristiana ${ }^{4}$ de El Salvador al contexto socio-político de los años setenta de dicho país. Es decir, intento indagar cómo o de qué manera el planteamiento liberador del cristianismo latinoamericano contribuyó al análisis social, económico y político de El Salvador en la década de los setenta.

Ahora bien, aquí debo hacer cuatro aclaraciones de fundamental importancia para la sana comprensión de mi trabajo de investigación. En primer lugar, aun cuando este esfuerzo de investigación parte de esa tesis establecida por Scannone, nuestro objetivo fundamental no consiste en desarrollar un tipo de estudio centrado en el análisis de algún filósofo o movimiento filosófico en particular con miras a desentrañar qué aportes pudieron haber dado a ese diálogo entre filosofía y cristianismo latinoamericano. En otras palabras, este trabajo de investigación parte de la tesis defendida por Scannone, pero se propone analizar la relevancia de la propuesta cristiana de liberación en un tipo de discurso 
no estrictamente filosófico, pero igualmente importante como modo de análisis y comprensión de la realidad ${ }^{5}$. En ese sentido, el presente trabajo pretende exponer algunos análisis de la sociedad salvadoreña que un grupo de cristianos hiciera en la década de los setenta a la luz de la idea de la liberación integral del ser humano. Dicho de otra manera, este trabajo constituiría un intento por participar de esa tradición investigadora latinoamericana que desde un tiempo para acá se ha denominado "Historia de las ideas". De ahí que el gran objetivo de mi investigación consista en mostrar cómo algunos cristianos salvadoreños analizaron y comprendieron su sociedad bajo el influjo de la renovación de la Iglesia a partir del Concilio Vaticano II y del análisis que del continente americano realizaron los obispos en Medellín. Esto nos conduce a la segunda aclaración.

A raíz de mi interés por analizar "discursos", no de especialistas en filosofía, sino de religiosos y laicos que desde su formación cristiana se dedicaron al análisis social, el presente trabajo tiene como fuente principal el boletín Justicia y Paz, que se comenzó a publicar en 1972 y cesó su publicación en $1980^{6}$. A juzgar por los comentarios de Monseñor Ricardo Urioste, dicho boletín gozó de mucha importancia como vehículo transmisor de conocimiento entre aquellos salvadoreños claramente identificados con los procesos liberadores ${ }^{7}$. Pero no estamos frente al aporte de reconocidos filósofos y/o teólogos, sino ante un tipo de discurso que da cuenta de la realidad social, económica y política de la sociedad salvadoreña desde principios y valores cristianos y, específicamente, desde la idea de "liberación”, misma ésta que, según Scannone, constituye un aporte original del cristianismo latinoamericano a la filosofía.

La tercera aclaración consiste en un conjunto de observaciones sobre la fuente investigada. Se exponen a continuación. Primera. Ciertamente, el boletín nace como una publicación adscrita a la iglesia salvadoreña, entiéndase la Institución. Es decir, surge con el apoyo de la Conferencia Episcopal de El Salvador (CEDES). Sin embargo, en este trabajo mantendremos la tesis, de carácter más amplio, de que los análisis presentes en dicho boletín más que pertenecer a la voz oficial de la iglesia son la expresión propia de un grupo de cristianos, tanto sacerdotes como laicos, comprometidos con la liberación de los pobres. Segunda. Justicia y Paz nace en marzo de 1972 de la mano del P. Fabián Amaya, con el objetivo de ser un periódico para las mayorías campesinas, y, con una 
clara orientación hacia la denuncia de la injusticia social y el anuncio de la liberación. Tercera. A juzgar por el mismo P. Fabián Amaya, Justicia y Paz tuvo amplia recepción en profesores, estudiantes y, por supuesto, los mismos campesinos. La mayor cantidad de lectores se ubicó en las zonas rurales. Cuarta. La elaboración del boletín estaba a cargo del P. Fabián Amaya — quien era el Director-, otros sacerdotes y un grupo de "diez campesinos de cinco zonas del país: Chalatenango, Aguilares, Suchitoto, Cojutepeque y Tecoluca. (...). Los campesinos asistentes son seleccionados por sus respectivas comunidades y a la vez son agentes de Justicia y Paz en sus cantones"8. Quinta. Se inició un tiraje de 500 ejemplares, pero para 1973 el tiraje aumentó a 7.000. En los cantones tuvo una distribución fija, mientras que en la ciudad fue muy poca. Las parroquias de San Salvador que lo distribuían eran pocas, sobre todo aquellas localizadas en los barrios marginales. Sexta. Hay que tener en cuenta que los datos concernientes a las observaciones cuarta y quinta tienen como fecha de referencia el último trimestre de 1973. Es decir, en estos aspectos del proceso de elaboración y publicación del periódico es muy probable que, más adelante, se hayan dado cambios importantes; esto debido a los cambios ocurridos en cuanto a los organismos responsables de su publicación. En cuanto a las demás observaciones, considero que mantienen su vigencia desde el primero hasta el último boletín publicado. Séptima. Para este trabajo no se han utilizado todos lo números publicados, únicamente se han seleccionado aquellos más representativos en el marco de la investigación. En las citas respectivas se dejará clara constancia de los números utilizados.

En cuarto lugar, a manera de hipoteca de trabajo: el presente ensayo vendría a ser apenas un apartado de un proyecto de investigación más amplio que tendría como núcleo fundamental los elementos y orientaciones antes señalados. Proyecto que bien podría ser continuado por mi persona o por cualquier otra, identificada e interesada por dicha cuestión.

Habiendo expuesto las aclaraciones pertinentes, procedo a continuación a señalar las partes fundamentales de este trabajo. Primero: haré unas someras anotaciones sobre el contexto histórico de El Salvador en la década de los 70. Segundo: expondré cuál es el concepto de sociedad salvadoreña que se maneja en el boletín antes descrito. Tercero: desarrollaré qué concepto o representación del campesino salvadoreño se construye en dicha fuente. Cuarto: abordaré el tema de la organización 
sindical campesina como camino hacia la liberación. Y, finalmente, aportaré unas conclusiones generales.

\section{Apuntes sobre el contexto histórico de los años 70 en El Sal- vador}

Pese al riesgo de caer en reduccionismos o en una mera narración de hechos, resulta de fundamental importancia exponer algunos acontecimientos que marcaron profundamente la vida de los salvadoreños durante la década referida.

Los inicios de la década de los 70 estuvieron marcados por diversos acontecimientos que pusieron de nuevo en evidencia que el orden social, político y económico estaba establecido según los intereses de las elites en el poder, entiéndase los militares y la oligarquía. Fue la guerra con Honduras (julio de 1969), quizás, el único hecho que unió a sectores antagónicos de la sociedad salvadoreña. A fines de junio de 1969 se declaró la creación del Partido de Unidad Nacional, éste sostuvo que los derechos humanos de los salvadoreños migrantes y la dignidad nacional del país debían de estar por encima de los intereses político-partidistas?. Sin embargo, una vez terminada la guerra dicho suceso fue motivo de acusaciones y disputas, sobre todo en las campañas electorales posteriores cercanas a 1969. Además, esto no debe perderse de vista, una de las causas principales de la emigración de salvadoreños hacia Honduras fue la estructura prevaleciente de la tenencia de tierra en El Salvador. En este país, desde la abolición de las tierras ejidales y comunales, paulatinamente la mayoría de campesinos se quedó sin tierras para sus cultivos de subsistencia. Según R. Cabarrús, para los años 70, el 1.5\% de los propietarios agrícolas controlaba la mitad de las tierras cultivables ${ }^{10}$. Las últimas propuestas de reforma agraria, la de Fidel Sánchez Hernández en 1970 y la de Arturo Armando Molina en 1975, perecieron a manos de la oligarquía terrateniente. Esto aumentó el descontento de los campesinos desposeídos, que eran la mayoría. Es decir, la guerra con Honduras unió y conmovió a los salvadoreños, y también captó la atención internacional, pero, en el fondo, la injusta distribución y tenencia de tierras fue una de las realidades que obligó a muchos campesinos a buscar fuentes de ingreso en el vecino país que luego, 1969, los expulsaría. Finalmente, sin mencionar los problemas en los que se vio el gobierno salvadoreño al recibir a miles de deportados, la economía sufrió un duro revés con la ruptura del Mercado Común Centroamericano, puesto que El Salvador era uno de los más beneficiados con dicho tratado económico. 
Por otro lado, las huelgas de 1968 y 1971 de la Asociación Nacional de Educadores (ANDES) fueron muy significativas, ya que miles de salvadoreños se solidarizaron con las demandas de los profesores. Respecto a la primera (1968), Ricardo Ribera afirma que: "El movimiento sería impactante para la sociedad salvadoreña y premonitorio del potente movimiento opositor de masas que se desarrollaría durante la década siguiente." ${ }^{11}$. Mejoras salariales y cambios en la legislación concerniente a la carrera docente fueron algunas de las exigencias planteadas por los educadores, al mismo tiempo se manifestaron en contra de la Reforma Educativa promovida por los EE.UU. El gobierno de turno intimidó y reprimió a muchos lideres del gremio, esto coadyuvó a la consecuente radicalización de muchos de ellos al optar por la lucha armada, lo cual finalmente se tradujo en una enorme lista de maestros asesinados en el transcurso de los 70.

En el campo político, las elecciones presidenciales de 1972 fueron las que terminaron de convencer a muchos salvadoreños que la única forma de conquistar el poder, y realizar cambios estructurales a favor de los más pobres, era a través de las armas. El Salvador había caído bajo el gobierno de los militares desde el golpe de estado de diciembre de 1931 que dejó como presidente al Gral. Maximiliano Hernández Martínez. 1972 significó la más alta posibilidad, para la mayoría de salvadoreños, de poner punto final a una época histórica durante la cual el poder político fue ejercido por los militares, en alianza con las elites económicas. Las esperanzas estaban empeñadas en la Unión Nacional Opositora. Estaba conformada por el Partido Demócrata Cristiano (PDC); el Movimiento Nacional Revolucionario (MNR) y la Unión Democrática Nacionalista (UDN). El candidato era el ingeniero José Napoleón Duarte. Pero el fraude perpetrado por el partido del gobierno, el Partido de Conciliación Nacional, frustró dichas esperanzas. Al final, la Asamblea Legislativa impuso el $1^{\circ}$ de julio de ese mismo año al Coronel Arturo Armando Molina como presidente de la república para un período de cinco años. Es decir, dicho acontecimiento profundizó la crisis socio-política de los años 70. En febrero de 1977 arribó a la presidencia el Gral. Carlos Humberto Romero como resultado de un nuevo fraude. Bajo el gobierno de éste se recrudeció la represión en el país. Pero su gobierno no duró sino hasta el 15 de octubre de 1979, fecha en que un nuevo golpe de estado - el último en lo que lleva de historia este país centroamericano- lo removió de su cargo, instaurando al mis- 
mo tiempo la Primera Junta Revolucionaria de Gobierno. En la nueva agenda de gobierno se contemplaron puntos como la reforma agraria y la nacionalización de la banca. Seguramente, la presencia de este tipo de cuestiones en la plataforma de gobierno de la junta era una forma de ir en contra de la opción por la guerra, que ya se hacía sentir con más fuerza. Pero esta junta, y las siguientes, fracasaron. El salvador estaba a las puertas de la guerra civil. Las posibilidades de llevar a cabo cambios estructurales mediante la vía cívico-política habían sido obturada por las dictaduras militares y por las elites económicas. La década de los setentas sirvió de momento histórico en el que se radicalizó la opción por la vía armada. Prueba de ello es que, excepto el Partido Comunista Salvadoreño (PCS), las restantes organizaciones que conformaron la guerrilla salvadoreña en 1980, el Frente Farabundo Martí para la Liberación Nacional (FMLN), surgieron durante dicha década. Las Fuerzas Populares de Liberación (FPL) se fundaron en 1970 (aunque se debe tener en cuenta que esta organización fue el resultado de una escisión del PCS); mientras que el Ejercito Revolucionario del Pueblo (ERP) nació en 1972. En 1975, como fruto de una escisión dentro de este último, surgieron las Fuerzas Armadas de Resistencia Nacional (FARN), y, en ese mismo año se fundó el Partido Revolucionario de los Trabajadores Centroamericanos (PRTC).

En el ámbito más específicamente económico, hay que decir que la política desarrollista, basada principalmente en los procesos de industrialización, que adoptó la economía salvadoreña durante la década de los sesenta terminó beneficiando únicamente a los grupos pudientes. En 1975, Rafael Menjívar afirmaba que "el ingreso real de la población no ha crecido en correspondencia con el nivel de crecimiento logrado por el sistema económico durante la década de los años sesenta" "12. En términos estadísticos, el mismo autor sostiene que para 1961, “(..) mientras el 1\% de la población con los ingresos más latos, percibe el 18\% del total de ingresos generados en ese año; el $60 \%$ de la misma percibe casi un porcentaje similar $(20.8 \%)^{\prime 13}$. Entonces, a lo largo de las décadas sesenta y setenta, la mayor parte de la población salvadoreña continúa padeciendo problemas de carencia de tierras, desempleo, subempleo, bajos ingresos, etc.; lo cual se traduce en pésimas condiciones de vida. 


\section{III.) Concepción de sociedad}

Durante la década de 1970, la Iglesia de El Salvador fue protagonista de la historia socio-política que estaba aconteciendo en dicho país. La Iglesia, apoyándose en el Vaticano II y en al Segunda Conferencia General del Episcopado en Medellín, asume un compromiso más abierto $\mathrm{y}$ responsable ante las injusticias producidas por una sociedad donde únicamente ciertas elites se benefician del orden político y de las riquezas que se generan. La iglesia asume el deber de la denuncia ante una sociedad donde conviven la miseria y la opulencia. Un ejemplo claro de esto lo encontramos en la publicación del boletín que ahora nos ocupa: Justicia y paz. En este boletín constatamos el aporte de un grupo de cristianos en el campo del análisis social. Ciertamente, encontramos diversos problemas sociales como objetos de análisis, según sea la coyuntura socio-política; pero, en términos generales, la idea de la existencia de una sociedad salvadoreña estructuralmente injusta es "el paradigma" desde el cual se analizan y se comprenden dichos problemas.

Para diciembre de 1972, en un modelo de "Examen de conciencia para Navidad y Año Nuevo" se plantea la siguiente interrogante: “ ¿Hemos sido solidarios con los que sufren la opresión de estructuras injustas y de los que sufren la dura explotación de sus propios hermanos?"14. En esta invitación a reflexionar aparece claramente la idea de una sociedad estructuralmente injusta. La pregunta que inmediatamente surge es qué se entiende por ese tipo de sociedad. Con este concepto se quiere señalar, fundamentalmente, la existencia de un orden social que atenta contra la dignidad humana. Más en concreto, sociedad estructuralmente injusta es aquella donde la praxis política, la actividad económica y el desarrollo cultural están en función de los intereses de unas elites; de tal manera que los grupos marginados o excluidos, que son la mayoría, viven en una serie de condiciones que no les permite realizar sus vidas en dignidad y libertad. Se trata de un tipo de condiciones socio-históricas que impiden la realización integral de la vida humana. Al respecto, Luis Armando González habla de "lastre estructural", entendido como "la marginación económica y social (sic) importantes sectores de la población, sobre todo de los sectores campesinos"15. En el boletín número 35, de 1974, se cita una de las cartas pastorales de Monseñor Luis Chávez y González ${ }^{16}$. En ella él sostiene que “... el Concilio Vaticano II ha sido bien claro en condenar estas situaciones de injusticia estructurada: '...cuanto ofende a la dignidad humana, dice el Concilio, como 
son las condiciones infrahumanas de vida, las detenciones arbitrarias, las deportaciones, la esclavitud, la prostitución, la trata de blancas y de jóvenes: o las condiciones laborales degradantes, que reducen al operario al rango de mero instrumento de lucro, sin respeto a la libertad y a la responsabilidad de la persona humana: todas estas practicas y otras parecidas son en sí mismas infamantes..."17.

Ya a mediados de 1972, el concepto de sociedad salvadoreña que aparece en el boletín es el de una sociedad que no permite el desarrollo de una vida digna para la mayoría de la población. En mayo de ese año se escribe lo siguiente: "No puede haber armonía social, y por lo tanto no puede haber paz social en el país, mientras no existe (sic) las condiciones que permitan a los trabajadores tanto manuales como intelectuales, la realización integral de sus destinos libres de la presión del miedo, del hambre, de la miseria y de la ignorancia" ${ }^{18}$.

Quiero partir de la cita precedente para poner en claro algunas denuncias por parte del boletín respecto de la vida política (miedo), económica (hambre, miseria) y cultural (ignorancia).

Política. En el boletín de agosto de 1972 se denuncia abiertamente la violación a los derechos humanos por parte de las autoridades hacia los dirigentes campesinos y obreros. Se dice que: “... una breve enumeración nos conduce a ver que, en el país ha habido persecución de dirigentes campesinos y obreros, que han sido privados de su libertad, que se les ha negado el derecho a asociarse y su derecho a la libertad de opinión. Se les ha negado su derecho a circular libremente dentro del territorio, su derecho a recibir informaciones y opiniones y a difundirlas" ${ }^{19}$.

Según los analistas, la paz es posible alcanzarla únicamente si hay justicia. Se hace necesaria una sociedad donde se respete la dignidad humana, donde se cumplan los derechos humanos para que la paz sea posible. La paz tiene su fundamento en la justicia social. Esto está en auténtica sintonía con la teología de la liberación que se desarrolló con gran fuerza a lo largo de la década de los setenta. Es más, otra cuestión de suma importancia con respecto éste trabajo, consistiría en investigar qué aportes —en caso de que así haya sido- pudo haber dado la teología de la liberación a los analistas del boletín; pero es una cuestión que por ahora está fuera de nuestros objetivos. Lo que sí es seguro es que la reivindicación de la justicia como realidad primaria y fundamental para conquistar la tan ansiada paz, por parte del boletín, está en clara concordancia con la teología latinoamericana de la liberación. Gustavo

\section{1}


Gutiérrez afirma lo siguiente: "Los profetas anuncian un reino de paz, pero la paz supone el establecimiento de la justicia: "el producto de la justicia será la paz, el fruto de la equidad, una seguridad perpetua” (Is. 32; 17; también Salmo 85), la defensa de los derechos de los pobres, el castigo de los opresores, una vida sin temor de ser esclavizados por otros, la liberación de los oprimidos”20.

Según Justicia y Paz: "No podemos hablar de paz cuando hay persecución de dirigentes campesinos y obreros, cuando hay fraude en procesos electorales, cuando se le niega al campesino el derecho de sindicalizarse. No podemos hablar de paz y derechos humanos a quién a veces a penas (sic) come unas tortillas con frijoles”21. El fraude mencionado es el de 1972; después del fracaso electoral y del intento de golpe de estado, el Ing. José Napoleón Duarte, candidato de la UNO, fue capturado, torturado y exiliado.

Economía. En septiembre de 1972 se denuncia que "las viviendas del sector rural no llenan las condiciones de higiene y seguridad ya que las personas que habitan en ellas están sujetas a toda clase de inclemencias del tiempo y están expuestas a sufrir toda clase de enfermedades"22. Al respecto, en su tesis L.A. González nos habla del "déficit habitacional en los sectores populares" 23 . Por otro lado, la tenencia y el uso de la tierra es otra fuente de desigualdades en la sociedad salvadoreña. Se dice que "la tierra está mal distribuida y está mal cultivada. Existen grandes extensiones de tierra en manos de unos cuantos. Esas grandes extensiones son las tierras más fértiles y con mejor acceso por carreteras" ${ }^{24}$. Las mejores tierras se dedican al cultivo de productos exportables: caña de azúcar, algodón, café. Mientras que para el cultivo del sustento básico del campesino, maíz y frijoles, se dejan las tierras más inútiles. Según los analistas, esa situación tiene su origen en la reforma agraria que se impuso en el último cuarto de siglo XIX. Como se sabe, la abolición de las tierras comunales y ejidales estuvo enmarcada en el proceso que consolidó al café como el producto primario de exportación de la economía salvadoreña. Desde la perspectiva del boletín, "esta reforma provocó la gran concentración de tierras en manos de muy pocos, y el hecho de que exista gran número de salvadoreños sin los medios materiales para lograr su sustento" 25 . En agosto de 1975 se vuelve a insistir en que a partir de entonces la situación agraria del campesino ha ido de mal en peor. Justicia y Paz afirma que la creación del ISTA (Instituto Salvadoreño de Transformación Agraria, creado a raíz de una ley decretada 
por la Asamblea Legislativa el 26 de junio de 1975) constituye un buen avance hacia la redistribución de la tierra, pero lamenta la exclusión del campesinado en la elaboración de dicho proyecto de transformación agraria ${ }^{26}$. Esta situación tenía un precedente cercano: A fines de 1969 los campesinos quedaron fuera de la convocatoria para el Congreso Nacional de Reforma Agraria que hizo la Asamblea Legislativa de ese entonces.

En el boletín Número 12 se presentan los resultados de una encuesta sobre las cortas de café, realizada a cinco jóvenes en 1971. Uno de ellos afirmó haber asistido a las cortas debido a que en su comunidad abunda el desempleo y el poco que hay es muy mal pagado, de tal manera que no se alcanza a cubrir las necesidades básicas. A la pregunta de "¿cómo se vive en las fincas de café?”, uno de los encuestados, llamado Félix, responde que: "Las condiciones de trabajo son muy malas porque hay que pagar $\phi 0.50$ de comida y $\phi 1.00$ de canasto. No hay medicina para los trabajadores, tienen que estar bien controlados por los policías de finca, por si uno protesta. Se vive como animales, se duerme en el cafetal, se come comida mal preparada, se sufre mucho frío" ${ }^{27}$. A la pregunta de "¿Qué piensas del ambiente y de las reacciones de los cortadores?", Francisco, otro de los jóvenes, responde lo siguiente: "El ambiente de vida del trabajador no es digno. Ya que los caballos, cerdos y vacas de los ricos tienen mejor comida, mejor modo de dormir. Sabemos que esto no es el plan de Dios, pues los animales no son hijos de Dios”28.

Los análisis mostrados dejan claro que la concentración de las mejores tierras en unas cuantas elites familiares es la causa de profundas desigualdades e injusticias en la sociedad salvadoreña. L.A. González sostiene que: "En términos generales, las condiciones socio-económicas de los sectores populares salvadoreños durante los 70 se muestran particularmente precarias a nivel salarial y laboral, así como a nivel de vivienda, educación y salud. Sin embargo, los sectores que más resienten esta marginación socio-económica son los sectores rurales”29.

Cultura. Con respecto a la educación, el boletín denuncia fundamentalmente dos hechos. Por un lado, resulta que la educación constituye un privilegio para los grupos pudientes; mientras que las grandes masas de campesinos quedan marginadas del proceso de aprendizaje escolar. Así, tenemos que, para 1971, de 1.081, 523 personas que viven en el campo, entre seis y veintinueve años de edad, únicamente 307, 938 asisten a la escuela, quedando fuera 773, 585. Así también, de 1.369, 284

\section{3}


personas de 10 y más años de edad que viven en el campo, únicamente 608, 462 saben leer, mientras que 760, 822 no saben leer ${ }^{30}$. Mientras que para el año de 1976 se estima que el analfabetismo de adultos en la capital es de $51 \%$ y en la zona rural de $65 \%{ }^{31}$. En general, la gente que vive en las zonas rurales en su mayoría queda marginada de la educación. Los colegios con excelencia académica están en la ciudad y al alcance de los grupos pudientes ${ }^{32}$. En términos de estructura económica, los problemas concernientes al analfabetismo son irrelevantes, puesto que la actividad económica demanda muy poca mano de obra calificada.

Por otro lado, se critica el divorcio existente entre los contenidos curriculares y la realidad en la que viven los niños campesinos. Ya los obispos de Medellín habían señalado que la enseñanza en nuestros países difícilmente podría ayudar al verdadero desarrollo de nuestras sociedades. Esto porque los programas de estudio son excesivamente "abstractos" y "formalistas". De ahí que desde el boletín se critique los siguiente: "Se les enseña historia a los niños pero no se les enseña a analizar a partir de esa historia de que las cosas cambian y de que los hombres somos los responsables de esos cambios. Se les enseña en Geografía a nuestros niños los nombres más raros de países y continentes que nunca conocerán, pero se nos olvida enseñar la estructura de nuestra tierra, su forma de tenencia y distribución. Se les habla de vivienda y de las diversas clases de vivienda pero se olvida de analizar el porque de las zonas marginadas" 33 .

\section{IV) El campesino salvadoreño}

Habiendo expuesto el tipo de sociedad que se ve y analiza desde el boletín Justicia y Paz en la década de los 70’s, no será muy difícil hacernos una idea del tipo de campesino que vive en El Salvador para esa época.

En primer lugar, tenemos a una población campesina viviendo en condiciones de pobreza o extrema pobreza. La gran mayoría de campesinos salvadoreños no cuenta con los recursos materiales y culturales para desarrollar una vida digna. Esto tiene mucho que ver con su situación de trabajo. El trabajo en las cortas de café, en las algodoneras y en los cañales es remunerado de forma injusta. Esto aparte de los actos arbitrarios, engaños y robos descarados por parte de los terratenientes. Los patrones pasan por encima de las leyes y abusan de los trabajadores. Por ejemplo: "1. Robando en las medidas y pesas. 2. Haciendo que se 
pague hasta $\varnothing 1.00$ por rama quebrada [esto con respecto a las cortas de café]. 3. Dando tareas de roza de caña tan grandes que es casi imposible terminarla solo uno en el día. 4. También no anotan en la planilla a todos. Por ejemplo si llegan grupos familiares o de amigos anotan a uno y los demás se quedan fuera de planilla y a éstos no les pagan el séptimo ni tienen derecho a comida" ${ }^{34}$.

A continuación se presenta parte del testimonio de un campesino que es recogido por el boletín número 18:

Si queremos trabajar a medias con el patrón, la cosa siempre es bien fregada; porque el patrón por cada manzana de milpa que nos arrienda, tenemos que trabajarle a él cuatro días de choto (gratis: N. del A.). Después nos obligan a abonar los cañales, que aunque si bien es cierto que nos pagan el abono de los cañales, esto supone que tenemos que abandonar nuestras milpas por varios días. Bueno, tenemos que pagar la mitad del abono, de la semilla y esto por adelantado y en efectivo y también con una condición: que tenemos que hacerle la milpa al patrón y también los cercos. Y como si esto fuera poco, se nos obliga a tapiscar la milpa verde, porque el patrón quiere sembrar caña ${ }^{35}$.

El trabajo, entonces, no es para el campesino una fuente de dignificación, sino mas bien una actividad que lo mantiene en condiciones de miseria. El trabajo mas que realizar al campesino, lo degrada.

Justamente a raíz de la pobreza en que vive, surge la figura del campesino emigrante. Muchos campesinos se trasladan a vivir a la ciudad con la esperanza de conquistar mejores condiciones de vida. Pero al encontrarse con el desempleo su gran objetivo queda frustrado. Esto no hace más que contribuir al aumento de las zonas marginales ${ }^{36}$. También hay que recordar los altos niveles de emigración tanto hacia Honduras como hacia los EE.UU. Para el año de 1969, según el Ministerio de Relaciones Exteriores de El Salvador — de aquella época- vivían en Honduras aproximadamente 250, 000 salvadoreños ${ }^{37}$.

Si retomamos el análisis del contexto cultural-educativo de la época, hay que tener muy en cuenta también la condición analfabeta del campesinado. A raíz de las profundas desigualdades del sistema educativo, el campesino promedio carece de una educación de largo plazo, gratuita y de calidad. Así, pues, no solamente estamos ante un campesino pobre y emigrante, sino también analfabeto. 
Finalmente, hay que mencionar la figura del campesino perseguido. Aquellos campesinos que asumieron el compromiso de luchar por sus derechos fueron perseguidos por las autoridades. La persecución se manifestaba a través de calumnias, amenazas, torturas y, en última instancia, terminaba con la vida de los campesinos. Toda forma de organización campesina sustentada en un discernimiento cristiano crítico y en una clara defensa de los derechos humanos era mal vista por el aparato de seguridad del estado; por eso se perseguía a los campesinos acusándolos de "comunistas". Ser un campesino con conciencia crítica significaba ser un individuo peligroso para el sistema socio-político que sustentaba los beneficios de las elites en el poder, por eso había que perseguir al campesino para escarmentarlo, encarcelarlo, torturarlo y/o eliminarlo.

\section{El campesino y su liberación}

Desde los análisis del boletín Justicia y Paz hay una clara postura a favor de echar a andar aquellos proyectos políticos que tengan como finalidad la liberación del campesino de las estructuras injustas que lo mantienen condenado a la miseria. Y el primer gran paso - en el que se insiste una y otra vez mediante el boletín- que el campesino debe dar es la organización: los campesinos deben organizarse para exigir el cumplimiento y respeto de sus derechos ${ }^{38}$. Esto debe ser el principio del proceso de liberación. La lucha por la libertad constituye un deber cristiano. En el boletín número 10 encontramos lo siguiente: "Luchemos para que nuestra Patria sea libre, en la que no haya engaño, opresión, ni maldad... TODO ESO SERÁ POSIBLE SI TÚ TRABAJAS POR CONSEGUIRLO”39.

Se insiste mucho en la necesidad de que los campesinos se organicen en sindicatos. Así, por ejemplo, se plantea la importancia de la creación de un sindicato "que luche por la aplicación de las leyes laborales, un sindicato que sepa defender los derechos del trabajador, y que no se venda al Patrón. Un sindicato que aúne a todos los trabajadores del campo para la defensa de sus derechos que les corresponden como ciudadanos y como personas. Estos logros hay que lograrlos (sic) a fuerza de mucha lucha y no solamente esperar que no los den desde arriba o nos lo regalen" ${ }^{40}$. La organización campesina se presenta como un imperativo. Y es que ya los obispos de América Latina habían dejado bien claro que los campesinos tienen derecho a la libre sindicalización: 
“(...) la organización sindical campesina y obrera, a la que los trabajadores tienen derecho, deberá adquirir suficiente fuerza y presencia en la

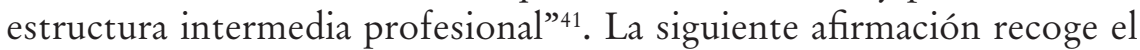
objetivo primordial y último de Justicia y Paz; “Todo el periódico está orientado a promover la liberación de los pobres, siendo el pobre por excelencia el campesino. En este punto el periódico es muy concreto: contribuye a crear conciencia de clase dentro del campesinado.”2

Ante una sociedad estructuralmente injusta, ante la miseria y la persecución que padece gran parte de los campesinos salvadoreños, un buen número de cristianos asume la tarea de concientizar a la población como camino preparatorio para la efectiva organización. A través de ésta se pueden lograr transformaciones que liberen a los campesinos de las estructuras opresoras. Claro, según Justicia y Paz existen otras formas de enfrentar esa dura realidad pero que no conducen a una verdadera y auténtica liberación, tal es el caso del alcoholismo y la drogadicción. El camino correcto comienza con la toma de conciencia crítica, y, la consecuente organización. La tarea de concientización, hay que decirlo, no fue asumida por una minoría, sino que hizo eco en una parte muy considerable de los cristianos católicos. Además, esto no debe perderse de vista, recordemos que la Iglesia misma (como Institución), bajo la conducción de los Arzobispos Mons. Luis Chávez y González y Mons. Oscar Arnulfo Romero, estuvo a favor de la reivindicación de los derechos humanos por parte de quienes padecían las injusticias sociales, económicas y políticas. Esto porque ya para los años 70's la Iglesia se había apartado de su tradicional "asistencialismo" y "paternalismo" y respaldaba las demandas autónomas de las organizaciones campesinas. Por un lado, la participación de cristianos laicos en el proceso de concientizacion-organización aportó incalculables frutos. En 1975 la Federación Cristiana de Campesinos Salvadoreños (FECCAS) y la Unión de Trabajadores del Campo (UTC) se articularon en una sola federación: la federación de Trabajadores del Campo (FTC), "la organización campesina más fuerte que ha conocido la historia del país" ${ }^{43}$. Pero por otro lado, la Iglesia Católica —entiéndase sectores pertenecientes a la jerarquía - inició su calvario como víctima de la represión del Estado. Se desató, por lo tanto, una persecución de cristianos laicos y de sacerdotes comprometidos con la liberación. El primer asesinato de un sacerdote sucedió en Aguilares en marzo de 1977: el Padre Rutilio Grande fue ultimado junto con dos campesinos. Podría decirse que este

\section{7}


acto inauguró la persecución y los asesinatos que sufriría en adelante la Iglesia a manos de los aparatos de seguridad del Estado.

Ahora bien, si la organización sindical campesina es el camino correcto hacia la plena liberación, ¿de qué liberación estamos hablando?, ¿de qué tipo de liberación?, ¿cuál es el fin de ese afán liberador?

Debe quedar claro que el planteamiento liberador que se hace desde Justicia y Paz está fundado en los principios cristianos. Esto podemos comprobarlo con la siguiente cita: "La lucha por la libertad de los hombres y de los pueblos, es por tanto un deber del cristiano. Pero en la visión cristiana, esta libertad no se reduce a tener u obtener una libertad, sino a ser libre de todo y de todos, menos de Dios”44.

La miseria económica, el analfabetismo y la persecución política son formas de injusticia que deben abolirse porque atentan contra la dignidad del hombre, es decir, atentan contra su condición de hijo de Dios. La Iglesia al haber asumido la opción preferencial por los pobres tiene que implicarse en su proceso de liberación. Pero se trata de una liberación de las estructuras que impiden la realización humana y hacia una auténtica comunión con Dios.

Los obispos reunidos en Medellín leen la situación de América Latina a la luz del Evangelio: "Es el mismo Dios que, en la plenitud de los tiempos, envía a su Hijo para que hecho carne venga a liberar a todos los hombres de todas las esclavitudes a que los tiene sujetos el pecado, la ignorancia, el hambre, la miseria y la opresión, en una palabra, la injusticia y el odio que tiene su origen en el egoísmo humano" ${ }^{45}$.

Se plantea la liberación de una gran parte de la población salvadoreña respecto de unas estructuras socio-políticas que no le permiten desarrollar una vida en dignidad y libertad. Pero no se trata de un proyecto que pretenda abolir unas estructuras que oprimen a una clase para construir otras en las que la clase opresora pase a ser la oprimida. Se trata de un proyecto liberador que pretende instaurar un tipo de sociedad donde todos los hombres puedan vivir dignamente, pero tampoco pretende colocar al hombre mismo en el lugar de Dios. Sino que se trata de una propuesta liberadora que quiere y busca cambios históricos a favor de una sociedad fraterna donde la justicia y la paz sean parte de la realización del Reino de Dios. Una sociedad fundada en el amor cristiano y no en el egoísmo. Como se leía arriba: "libre de todo y todos, menos de Dios”. 
Lejos de toda crítica a este planteamiento, lo fundamental acá radica en el hecho de que la construcción de esa nueva sociedad donde impere la justicia y la paz será posible únicamente si aquellos que sufren el hambre, la ignorancia y la persecución asumen con conciencia crítica y convicción la tarea de su propia praxis liberadora. Queda claro aquí que el planteamiento liberador del cristianismo no es recepcionado por mentes filosóficas dedicadas a pensar la liberación del ser humano, al estilo Dussel y Sacannone. Lo que tenemos es un valioso y sistemático esfuerzo de hombres salvadoreños que desde su formación cristiana se dedican a analizar la realidad salvadoreña, a manera de concientizar a aquellos que padecen la miseria y la persecución que el principio y el camino de su liberación comienza con la organización sindical para la exigencia del cumplimiento y respeto de sus derechos. Aclaración ésta que no pretende menospreciar esto último, sino que, al contrario, sacarlo a la luz y constatar la enorme importancia de este tipo de discursos.

Con ello he pretendido situarme en las siguientes palabras de N. Bobbio: "La historia de las ideas o de las ideologías o de los ideales es entendida aquí como historia de la conciencia que los intelectuales tienen de su tiempo, de las categorías mentales que emplean en cada ocasión para comprenderlo, de los valores que adoptan para aprobarlo o para condenarlo, de los programas que formulan para transformarlo" ${ }^{46}$.

\section{Conclusiones}

Inspirados en el Vaticano II y en II Conferencia del Episcopado Latinoamericano en Medellín, encontramos en el boletín Justicia y Paz un conjunto de análisis del contexto socio-político de El Salvador de la década de los 70's. La tesis central es que la mayor parte de la población salvadoreña vive en la pobreza, no tiene acceso a educación y, cuando reclama por sus derechos, es perseguida por los sistemas de seguridad del estado, que están al servicio de los intereses económicos y políticos de las elites. El Salvador es una sociedad estructuralmente injusta. Estamos, entonces, ante un campesino pobre, analfabeto, perseguido y emigrante, esto cuando sale del campo en busca de mejores oportunidades. De ahí que muchos análisis del boletín insistan en la necesidad y la urgencia de que los campesinos se organicen en sindicatos para que luchen por su liberación, se apela a la unión de todos los campesinos. Pero no se trata de una propuesta liberadora que pretenda abolir la opresión actual por otra. Tampoco se trata de la búsqueda de una nueva

\section{9}


sociedad donde el ser humano sea el centro universal. Se trata de una propuesta liberadora cristiana. En este sentido, la praxis liberadora se entiende como parte de la construcción del Reino de Dios. Se pretende luchar por una sociedad justa y pacífica pero fundada en el amor de Dios.

Pero lejos de todo cuestionamiento a esta propuesta de liberación humana, lo fundamental aquí consiste en que se parte del principio de que los procesos liberadores deberán correr por cuenta de los hombres mismos. Y termino con la frase que he colocado al inicio de mi trabajo: "La liberación de América Latina brotará de nuestros brazos hermanos, manos, nervios, sangre; brotará, es cierto, como la cosecha que el sudor arranca del fondo de la tierra”.

Notas

1 Este trabajo fue presentado en el VIII Congreso Centroamericano de Historia, celebrado en Antigua Guatemala, Guatemala, del 10 al 14 de julio de 2006. Agradezco a Rafael Flores, Director del Archivo Histórico del Arzobispado de San Salvador, y, a Rubén Ortíz, Auxiliar Archivista, la paciencia y la amabilidad que me obsequiaron durante mi proceso de investigación.

2 J. C. Scannone, "Liberación. Un aporte original del cristianismo latinoamericano", en J. G. Caffarena (Ed.), Religión. Trotta, Madrid, 1993, pp.93-105.

3 Para una visión general de lo que fue el surgimiento de la "Filosofía de la liberación”, consultar: C. Beorlegui, Historia del pensamiento filosófico latinoamericano. Universidad de Deusto, Bilbao, 2004, cap.10.

4 Entiéndase Iglesia Católica, lo cual no quiere decir que este trabajo vaya a centrarse en la institución como tal, sino en aquella praxis identificada con dicha Iglesia. Y, por supuesto, aquella praxis que reúne aquellos cristianos comprometidos con un cambio social como forma de liberación.

5 Un trabajo estrictamente filosófico o teológico que pretenda asumir, rebatir, criticar o dialogar con la tesis de Scannone, desde la producción teológica y filosófica de El Salvador en la década de los setenta y ochenta, tendrá que adentrarse, necesariamente, en las profundidades y originalidades de la teología de la liberación y la filosofía de la liberación de Ignacio Ellacuría (1930-1989).

6 Para efectos de las citas que haré del boletín, debo hacer las siguientes aclaraciones. En primer lugar, de las 85 ediciones del boletín en ninguna de ellas aparecen los autores respectivos de los diversos análisis; se trata de textos anónimos. En este sentido, cuando tenga que referirme a ellos, usaré expresiones como: "según Justicia y Paz"; "según los analistas"; etc. En segundo lugar, a lo largo de la década podemos apreciar cambios en lo que podríamos llamar la "autoría general” del boletín. Los tres "grandes autores" son los siguientes: la Comisión Pastoral del Senado Presbiterial (que publicó los números del 6 al 15); la Comisión Justicia y 
Paz (que publicó los números del 16 al 43); las Comunidades Rurales Cristianas (quienes publicaron desde el número 44 hasta el 85 , que es el último y no aparece numerado). Con respecto a los números 2 y 4, el primero aparece bajo la dirección del Organo Informativo del Arzobispado; mientras que el otro, a cargo del Organo Informativo del Secretariado Social Interdiocesano. La colección del boletín en la que se ha basado nuestra investigación se encuentra en el Archivo Histórico del Arzobispado de San Salvador, El Salvador. Los únicos números que no se encuentran en el Archivo son: 1, 3, 5, 7 y 17.

7 Esta afirmación se ha extraído de una entrevista concedida por Monseñor Ricardo Urioste al autor de este ensayo.

8 A. C. Cepeda, et al, "Orientación y Justicia y Paz: reformismo y radicalismo en la iglesia salvadoreña”, Revista Estudios Centroamericanos (ECA), 230, 1973, pp.705727.

$9 \quad$ Cfr. S. Webre, José Napoleón Duarte y el Partido Demócrata Cristiano en la politica salvadoreña, 1960-1972. UCA Editores, San Salvador, 1985, pp.141-183.

10 Cfr. L.A. González, "Izquierda marxista y cristianismo en El Salvador, 1970-1992 (un ensayo de interpretación)". Tesis para obtener el título de Maestría en Ciencias Sociales, FLACSO, México, 1994, p.151.

11 R. Ribera, "El año histórico de 1968. Diez acontecimientos que cambiaron el mundo”, Realidad, No 104, 2005, pp. 241-268.

12 R. Menjivar, El Salvador: impulso y crisis del desarrollismo. Modelo en perspectiva. San Salvador, 1975, p.59.

13 Ibídem.

14 "Les doy una gran noticia para todo el pueblo: hoy les ha nacido un liberador", Justicia y Paz, número 13, 1972, p.6. En adelante el boletín se citará de la siguiente manera: J.P.

15 L.A. González, op. cit., p.134.

16 Mons. Luis Chávez y González fue Arzobispo de San Salvador desde septiembre de 1938 hasta febrero de 1977

“Mons. Chávez: 50 años de servicio a la comunidad”, J.P., número 35, 1974, p.7.

18 "Lo que interesa es el hombre”, J.P., número 4,1972, p.3.

“La paz es posible”, J.P., número 9, 1972, p.6.

Citado por S. Silva Gotay, "El pensamiento religioso", en Leopoldo Zea (Coord.), América Latina en sus ideas. Siglo XXI, México, D.F., 1986, pp.118-154.

“La paz es posible...”, J.P., número 14, 1973, p.9.

“Liberación: aspiración de un pueblo, 1821-1972”, J.P., número 10, 1972, p.6.

Cfr. L.A. González, op. cit., p.143.

Ibidem.

\section{1}


“América Latina: un pueblo que vive ansias de liberación”, J.P., número 11, 1972, p.6.

"Reforma agraria: con estas manos y mi fe”, J.P., número 44, 1975, p.6.

"Nosotros queremos vivir, pero algunos explotadores no quieren!(Sic.)", J.P., número 12, 1972, p.2.

Ibídem.

L.A. González, op. cit., p.149.

Cfr. “¿La enseñanza al servicio del pueblo?”, J.P., número 15, 1973, pp.4-5.

“Educación: ¿cómo subirá el pueblo?”, J.P., número 51, 1976, p.3.

Cfr. S. Montes, "Visión sociológica de la realidad educativa salvadoreña”, Revista Estudios Centroamericanos (ECA), 271, 1971, pp.250-263.

“¿La enseñanza al servicio del pueblo?”, J.P., número 15, 1973, p.7.

“Causas y víctimas”, J.P., número 27, 1974, p.2 *Gratis.

“Nuestra fuerza es unidad y solidaridad”, J.P., número 18, 1973, p.1.

Cfr. "Nuestra respuesta: la organización frente a la ambición de pocos”, J.P., número 29, 1974, p.7.

Cfr. S. Mantilla, "Los Hechos”, Revista Estudios Centroamericanos (ECA), 254-255, 1969, pp.393-398.

Cfr. L.A. González, op. cit., p.167.

“Liberación: aspiración de un pueblo, 1821-1972”, J.P., número10, 1972, p.10.

“Nuestra fuerza es unidad y solidaridad”, J.P., número18, 1973, p.9.

Los textos de Medellín y el proceso de cambio en América Latina. UCA Editores, San Salvador, 1977, p.29.

A. C. Cepeda, et al, "Orientación y Justicia y Paz ante la dimensión política del mensaje cristiano”, Revista Estudios Centroamericanos (ECA), 303-304, 1974, pp.59-79.

43 L.A. González, op. cit., p.193.

“Liberación: aspiración de un pueblo, 1821-1972”, J.P., número 10, 1972, p.11.

Ibidem.

Citado por J. Pinedo C., "Identidad y método: aproximaciones a la historia de las ideas en América.

Latina", en H. Cansino Troncoso, et al, (Eds.), Nuevas perspectivas teóricas y metodológicas de la Historia intelectual de América Latina, Iberoamericana, Madrid, 1999. 
- AA.VV., Iglesia de los pobres y organizaciones populares. UCA Editores, San Salvador, 1979.

- Beorlegui, C., Historia del pensamiento filosófico latinoamericano. Universidad de Deusto, Bilbao, 2004.

- Cancino Troncoso, H./Klengel, S./Leonzo, N. (Eds.), Nuevas perspectivas teóricas y metodológicas de la historia intelectual de América Latina. Iberoamericana, Madrid, 1999.

- Cepeda, A. C., et al, "Orientación y Justicia y Paz: reformismo y radicalismo en la iglesia salvadoreña”, Revista Estudios Centroamericanos (ECA), 300, 1973.

- Cepeda, A. C., et al, "Orientación y Justicia y Paæ: ante la dimensión política del mensaje cristiano”, Revista Estudios Centroamericanos (ECA), 303-304, 1974.

- Congregación para la Doctrina de la Fe, Instrucción sobre libertad cristiana y liberación.1986.

- Ellacuría, I., Veinte años de historia en El Salvador (1969-1989). Escritos politicos I y II. UCA Editores, San Salvador, 1993.

- Gómez Caffarena, J. (Ed.), Religión. Trotta, Madrid, 1993.

- González, L.A., "Izquierda marxista y cristianismo en El Salvador, 19701992 (un ensayo de interpretación)". Tesis para obtener el título de Maestría en Ciencias Sociales, FLACSO, México, 1994.

- Gordon, S., Crisis política y guerra en El Salvador. Siglo XXI, México, D.F., 1989.

- Los textos de Medellin y el proceso de cambio en América Latina. UCA Editores, San Salvador, 1977.

- Mantilla, S., "Los Hechos", Revista Estudios Centroamericanos (ECA), 254255, 1969.

- Martínez Peñate, O., El Salvador: historia general. Nuevo Enfoque, San Salvador, 2002.

- Menjivar, R., El Salvador: impulso y crisis del desarrollismo. Modelo en perspectiva. San Salvador, 1975. 
- Montes, S., "Visión sociológica de la realidad educativa salvadoreña", Revista Estudios Centroamericanos, 271, 1971.

- Ribera, R., "El año histórico de 1968. Diez acontecimientos que cambiaron el mundo", Revista de Ciencias Sociales y Humanidades (REALIDAD), 104, 2005.

- Sols Lucia, J., La teología histórica de Ignacio Ellacuría. Trotta, Madrid, 1999.

- Webre, S., José Napoleón Duarte y el Partido Demócrata Cristiano en la política salvadoreña, 1960-1972. UCA Editores, San Salvador, 1985.

- White, A., El Salvador. UCA Editores, San Salvador, 1987.

- Zea, L. (Coord.) América Latina en sus ideas. Siglo XXI, México, D.F., 1986. 